\title{
THE SIGNIFICANCE OF UNWILLINGNESS TO BE TESTED
}

\author{
By F B KNIGHT, State University of Iowa
}

As a pedagogical device in introducing the 'mental test' to the teachers of a county in Iowa, I had the teachers take Thorndike's College Entrance Examination, Part I At the time of taking the test the teachers were given the choice of signing their names or not as each saw fit They were assured that no administrative use of any kind would be made of the scores. The superintendent would not be informed of the relative success of any teacher. However, those teachers who signed their names to their tests would be told what scores they made and how their scores compared with scores made by college students, stenographers, soldiers, and the like

There were 65 teachers in the group, 39 signed their names, 26 did not. The distributions of these two groups are as follows

$\begin{array}{ccc}\text { Score } & \begin{array}{c}\text { Frequency of } \\ \text { scores on signed papers }\end{array} & \begin{array}{c}\text { Frequency of } \\ \text { scores on unsigned papers }\end{array} \\ 40 & & 1 \\ 45 & & 2 \\ 50 & 1 & 3 \\ 55 & 1 & 1 \\ 60 & & 2 \\ 65 & 2 & 2 \\ 70 & 1 & 3 \\ 75 & 3 & 4 \\ 80 & 4 & 2 \\ 85 & 1 & 2 \\ 90 & 5 & 5 \\ 95 & 3 & 1 \\ 100 & 4 & \\ 105 & 5 & 1 \\ 110 & 2 & \\ 115 & 3 & \\ 120 & & \\ 125 & 1 & \\ 130 & 1 & \\ 135 & 2 & \\ 140 & 1 & \end{array}$

The average score of the signed papers was 100 .

The average score of the unsigned papers was 75 . Only 


\section{SIGNIFICANCE OF UNWILLINGNESS TO BE TESTED}

four of the 26 unsigned papers equalled or exceeded the average of the signed group Only 5 of the 39 signed papers were as low or lower than the average of the unsigned tests We have very definite contrast in performance between these two groups Chance variations even with as small a group as this would be an unlikely explanation of the difference of the two distributions

Although we have too few cases upon which to base a certain conclusion it is evident that unwillingness to sign one's name to a mental test may be an unconscious confession of probable inability to do well Willingness or even desire to know how you compare with others is associated with relatively good scores This explanation seems to me more reasonable than that unwillingness meant becoming modesty or willingness inordinate forwardness Should not one's attitude toward a test be of definite diagnostic a1d ? 